\title{
EFFECTIVENESS OF TEACHING PROGRAMME ON KNOWLEDGE, ATTITUDE AND PRACTICES REGARDING THE HIV/AIDS AMONG PREGNANT WOMEN IN LADY GOSHEN HOSPITAL, MANGALORE - KARNATAKA
}

Narayani B. $\mathrm{H}^{1}$, Shakuntala ${ }^{2}$.
1. Assistant Professor, Department of OBG, Yenepoya Medical college
2. Superintendent Lady Goshen hospital, Mangalore.

\author{
CORRESPONDING AUTHOR: \\ Narayani. B. H, \\ Consultant in Fetal Medicine, \\ Mangalore Fetal Medicine Centre, \\ Kankanady, Mangalore. \\ E-mail: bandi_dd@yahoo.com
}

\section{HOW TO CITE THIS ARTICLE:}

Narayani B. H, Shakuntala. "Effectiveness of Teaching Programme on Knowledge, Attitude and practices Regarding the HIV/AIDS among Pregnant Women in Lady Goshen Hospital, Mangalore-Karnataka". Journal of Evolution of Medical and Dental Sciences 2013; Vol2, Issue 25, June 24; Page: 4548-4553.

\begin{abstract}
In India, several thousand HIV-infected babies are expected to be born every year.(i) MATERIALS \& METHODS: The present study is hospital based intervention study conducted in Government Lady Goshen Hospital, Mangalore. Study subjects were 100 in number recruited from women attending antenatal clinic, by random selection. They were initially assessed for KAP regarding HIV/AIDS by intervening using the interview schedule. After the assessment the participants were educated about HIV/AIDS by trained counselors using visual aids in local language then same KAP schedule was utilized to find out the effectiveness of the teaching programme. This was done as daily basis for 3 pregnant women on all working days. Observations revealed that level of knowledge was significantly higher in pregnant women from upper income group than low income group $(\mathrm{P}<0.05)$ and higher education than those who dint study $(\mathrm{P}<0.05)$. (iv) In pre-test session majority of women knew about HIV i.e. 95(95.00\%), but were unaware whether HIV positive mother can transmit infection to her baby 55(55.00\%). CONCLUSION: The level of awareness and knowledge of HIV/AIDS among pregnant women attending our antenatal clinics seems to be superficial; more education and knowledge about mother-to-child transmission are needed in India (v).
\end{abstract}

KEY WORDS: HIV/AIDS, MTCT.

Key message: More education and knowledge about mother-to-child transmission are needed in our country.

INTRODUCTION: In India, several thousand HIV-infected babies are expected to be born every year.(i) The rising prevalence of HIV among pregnant women in rural India is of great concern.(ii) Prenatal voluntary counseling and HIV testing (VCT) is critical to prevent mother-to-child transmission of HIV (PMTCT). Despite effective intervention, the identification of HIV infected pregnant women prior to delivery is a major problem. 
Pregnant women susceptible to HIV and its transmission to the fetus provide a unique opportunity for implementing preventive strategy against HIV infection of newborn babies. The study from Lusaka, Zambia suggests that pregnant mothers and their families need more education about MTCT of HIV. (iii)

\section{AIMS AND OBJECTIVES:}

i) To assess knowledge, Attitude and Practices of HIV, amongst pregnant women attending Lady Goshen Hospital.

ii) To educate the study subjects regarding HIV/AIDS.

iii) To assess the effectiveness of teaching programme on knowledge, Attitude and Practices among pregnant women attending hospital.

\section{MATERIALS \& METHODS:}

STUDY DESIGN: The present study is hospital based intervention study.

STUDY DURATION: July 2010 to Jan 2011.

STUDY AREA: The present study was conducted in Government Lady Goshen Hospital, Mangalore. It is maternity hospital providing care to people of Dakshin Kannada.

STUDY SUBJECTS: Pregnant women attending hospital, 100 in number by random selection.

INCLUSION CRITERIA: Study subjects were recruited from pregnant women attending antenatal clinic for first time, regardless of gravid status and duration of pregnancy and who gave willingness to participate in the study.

EXCLUSION CRITERIA: Not willing to participate in the study and very sick unable to communicate.

SAMPLING: Among all pregnant women attending antenatal clinic, 3 women were selected randomly using random number table on daily basis.

\section{DATA COLLECTION:}

STUDY TOOLS - KAP schedule for pregnant women regarding HIV. Assessment KAP of pregnant women:

Pre-test: Total sum of 100 pregnant women were initially assessed for KAP by intervening using the interview schedule. The schedule had items on socio-demographic characteristics and questions related to causation, transmission, signs \& symptoms, prevention and control of HIV/AIDS. The schedule was pre-tested among 10 pregnant women and finalized. After the assessment the participants were educated about HIV/AIDS by trained counselors using visual aids in local language. The teaching programme which focused on various aspects of HIV/AIDS including routes of transmission, symptoms of the disease and preventive measures. The teaching programme was for 15 minutes. 
Post-test: After teaching programme, the same KAP schedule was utilized to find out the effectiveness of the teaching programme. This was done as daily basis for 3 pregnant women on all working days.

ETHICAL ISSUES \& CONFIDENTIALITY: Permission from institution and the consent taken from the study subjects were taken. Patient privacy was an important consideration for a study of this nature and the adequate steps were taken to ensure the confidentiality.

\section{RESULTS:}

Table I: Demographic characteristics of pregnant women $(n=100)$

\begin{tabular}{|l|l|l|}
\hline Age (years) & Number & $\%(\mathrm{n}=100)$ \\
\hline$<20$ & 05 & 05.0 \\
\hline $20-25$ & 54 & 54.0 \\
\hline $25-30$ & 26 & 26.0 \\
\hline $30-35$ & 13 & 13.0 \\
\hline$>35$ & 02 & 02.0 \\
\hline
\end{tabular}

Table II: Education

\begin{tabular}{|l|l|l|}
\hline \multicolumn{1}{|c|}{ Education } & Number & \% (n=100) \\
\hline Illiterate & 14 & 14.0 \\
\hline Up to Primary & 24 & 24.0 \\
\hline Junior High School/High school & 29 & 29.0 \\
\hline Intermediate & 22 & 22.0 \\
\hline Graduate and above & 11 & 11.0 \\
\hline
\end{tabular}

Table III: Occupation

\begin{tabular}{|l|l|l|}
\hline Occupation & Number & $\%(\mathrm{n}=100)$ \\
\hline House wife & 68 & 68.0 \\
\hline Private Service & 11 & 11.0 \\
\hline Government Service & 02 & 02.0 \\
\hline Laborer/Agricultural & 19 & 19.0 \\
\hline
\end{tabular}

Table IV: Socio-economic status

\begin{tabular}{|l|l|l|}
\hline Socio-economic status & Number & $\%(\mathrm{n}=100)$ \\
\hline Upper class & 0 & 0.0 \\
\hline Upper middle class & 02 & 02.0 \\
\hline Middle class & 52 & 52.0 \\
\hline Lower middle class & 40 & 40.0 \\
\hline Lower class & 06 & 06.0 \\
\hline
\end{tabular}


Table V: Pre-test KAP of Pregnant Women depending on demographic features ( $n=100)$

\begin{tabular}{|l|l|l|}
\hline Education level & Number of correct answer answers & $\%$ \\
\hline Illiterate & 25 & 17.85 \\
\hline Up to Primary & 96 & 40.00 \\
\hline Junior High School/High school & 179 & 61.72 \\
\hline Intermediate & 176 & 80.00 \\
\hline Graduate and above & 103 & 93.63 \\
\hline \multicolumn{2}{|l|}{} \\
\hline Occupation & Number of correct answer answers & $\%$ \\
\hline House wife & 448 & 65.88 \\
\hline Private Service & 67 & 60.90 \\
\hline Government Service & 14 & 70.00 \\
\hline Laborer/ Agricultural & 44 & 23.15 \\
\hline & \multicolumn{2}{|l}{} \\
\hline Socio-Economic Status & Number of correct answer answers & $\%$ \\
\hline Upper Class & 0 & 00.00 \\
\hline Upper middle class & 15 & 75.00 \\
\hline Middle class & 321 & 61.73 \\
\hline Lower middle class & 230 & 57.50 \\
\hline Lower class & 13 & 21.66 \\
\hline
\end{tabular}

Table Vi: Post-test KAP of Pregnant Women depending on demographic features

\begin{tabular}{|l|l|l|}
\hline Education level & Number of correct answer answers & $\%$ \\
\hline Illiterate & 116 & 82.85 \\
\hline Up to Primary & 225 & 93.75 \\
\hline Junior High School/High school & 286 & 98.62 \\
\hline Intermediate & 219 & 99.54 \\
\hline Graduate and above & 110 & 100.00 \\
\hline \multicolumn{2}{|l|}{} \\
\hline Occupation & Number of correct answer answers & $\%$ \\
\hline House wife & 658 & 96.76 \\
\hline Private Service & 110 & 100.00 \\
\hline Government Service & 20 & 100.00 \\
\hline Laborer/ Agricultural & 168 & 88.42 \\
\hline & \multicolumn{2}{|l|}{} \\
\hline Socio-Economic Status & Number of correct answer answers & $\%$ \\
\hline Upper Class & 0 & 00.00 \\
\hline
\end{tabular}




\section{ORIGINAL ARTICLE}

\begin{tabular}{|l|l|l|}
\hline Upper middle class & 20 & 100.00 \\
\hline Middle class & 506 & 97.30 \\
\hline Lower middle class & 382 & 95.50 \\
\hline Lower class & 48 & 80.00 \\
\hline
\end{tabular}

Pre-test KAP was high in graduated (93.63\%) and women who were educated till the intermediate (80\%).But it was very less in women who were not educated $(17.85 \%)$ ).KAP was high in working women and in women who were house wife( $>60 \%)$, while it was less in laborer $(23.15 \%)$. Socioeconomic status also played important role in KAP regarding HIV in pregnant women.KAP was very less in lower socio-economic status women, whereas KAP was higher in middle class of women.

Observations revealed that level of knowledge was significantly higher in pregnant women from upper income group than low income group $(\mathrm{P}<0.05)$ and higher education than those who dint study $(\mathrm{P}<0.05)$. (iv)

Post-test KAP improved in all categories of pregnant women.

DISCUSSION: The present study reflects that the $54.00 \%$ of pregnant women belonged to the age group of 20-25 years. The illiterate (14.00\%) study subjects had lowest awareness, knowledge of HIV/AIDS. Out of total 100 subjects, majority of them had heard of HIV/AIDS i.e. 95(95.00\%) but were unaware whether HIV positive mother can transmit infection to her baby 55(55.00\%). Even a direct question as how can HIV transmission from a positive mother to her baby be prevented was incorrectly answered by 57(57.00\%). It says that even they knew about HIV infection but knowledge regarding MTCT was poor. But post -test knowledge regarding MTCT improved to $>92.00 \%$. And 31(31.00\%) women were against isolating HIV patients which improved to 98(98.00\%) after training.

In our study, the higher educational and socioeconomic statuses of pregnant women were associated with the increase in awareness towards HIV/AIDS which is similar to other studies carried out in different parts of India. There was a rising trend about knowledge on modes of transmission with various educational levels.

CONCLUSION: The level of awareness and knowledge of HIV/AIDS among pregnant women attending our antenatal clinics seems to be superficial; more education and knowledge about mother-to-child transmission are needed in India (v). Since awareness is the only key to the prevention of HIV/AIDS, there is an urgent need to increase the awareness about HIV/ AIDS, especially among the low socio economic, illiterate people of the community using all methods of mass media and intensive information, education and communication (IEC) activities by use of local folk media.(vi)

ACKNOWLEGEMENT: I take this opportunity to express my sincere gratitude and heartfelt thanks to Dr. Shakuntala. Superintendent, Lady-Goshen hospital and Mr. Ajith Rai for their co-operation, participation and creative inputs during the project. 


\section{ORIGINAL ARTICLE}

\section{REFERENCES:}

1. Rahbar T, Garg S, Tripathi $\mathrm{R}$ et al. "Knowledge, attitude, behavior and practice (KABP) regarding HIV/AIDS among pregnant women attending PPTCT programme in New Delhi". J Commun Dis. 2007 Sep; 39(3):179-84.

2. Rogers A, Meundi A, Amma A et al. HIV-related knowledge, attitudes, perceived benefits, and risks of HIV testing among pregnant women in rural Southern India. AIDS Patient Care STDS. 2006 Nov; 20(11):803-11

3. Petrovic K, Maimbolwa M, Johansson E. Midwifery. Primiparous mothers' knowledge about mother-to-child transmission of HIV in Lusaka, Zambia. 2009 Dec; 25(6):e1-e10. Epub 2007 Dec 31.

4. K.S. Negi, S.D Khandpal, Ashish Kumar et al. Knowledge, Attitude and Perception about HIV/AIDS among Pregnant Women in Rural Area of Dehradun JK SCIENCE Vol. 8 No. 3, JulySeptember 2006133

5. Singh MB, Chaudhary RC, Haldiya KR Knowledge and attitudes of pregnant women regarding AIDS in a semi arid area of Rajasthan. J Commun Dis. 1997 Jun; 29(2):139-44.

6. Abiodun MO, Ijaiya MA, Aboyeji PA. Awareness and knowledge of mother-to-child transmission of HIV among pregnant women. J Natl Med Assoc. 2007 Jul; 99(7):758-63. 